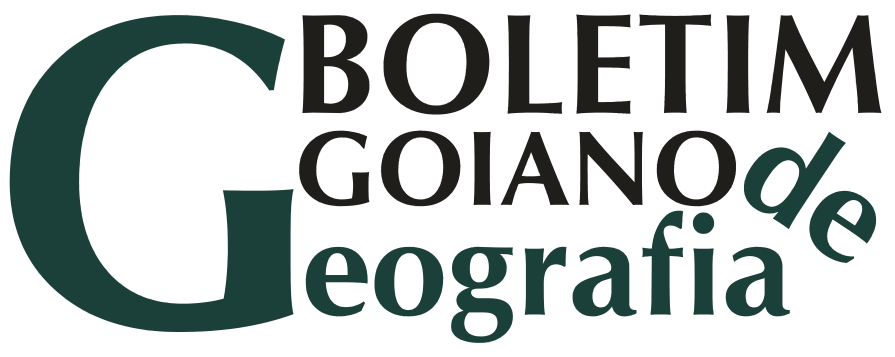

INSTITUTO DE ESTUDOS

SÓCIO-AMBIENTAIS/GEOGRAFIA

VOL. 23 - No 1 - JAN./ JUN. 2003

$\infty$
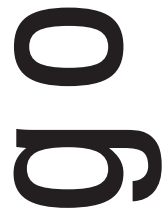

$\square$
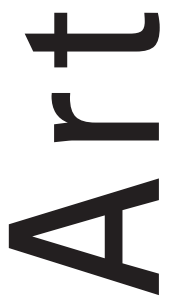


\title{
INDÚSTRIA AUTOMOBILÍSTICA BRASILEIRA NOS ANOS 90: UMA NOVA TERRITORIALIZAÇÃO*
}

\author{
Ronaldo da Silva**
}

\section{Resumo}

Este artigo tem como objetivo compreender a nova configuração territorial da indústria automobilística no Brasil durante os anos 90. Nesse período, o Brasil foi um dos países mais importantes do mundo na recepção de investimento externo direto. A moeda estável, uma maior inserção no processo de globalização e as políticas de abertura de mercado criaram as bases desejadas pelas corporações multinacionais do setor automobilístico. Houve também uma forte competição (guerra fiscal) entre governos municipais e estaduais com perversas conseqüências para o fundo público, para o desenvolvimento regional e para o sistema republicano brasileiro.

Unitermos: Indústria Automobilística/ Guerra Fiscal/ Nova Territorialização.

\section{O cenário da indústria automobilística brasileira}

Este texto busca discutir a renovação do setor automobilístico brasileiro nos anos 90, enfatizando a nova articulação da indústria automotiva no território brasileiro. O contexto socioespacial e histórico dessa abordagem é o Brasil dos anos 90 da era FHC. Nele se aprofundaram a reforma neoliberal do Estado e a inserção subordinada do país na globalização, com o predomínio do capital financeiro e com a abertura e desregulamentação do mercado interno. Nesse período houve uma disputa predatória, feita via guerra fiscal pelos Estados, para sediar investimentos produtivos de grandes corporações nacionais e internacionais. A disputa interestadual pelas indústrias automotivas ganhou relevo por seus elevados investimentos, geração de empregos, impostos e extensa cadeia

* O presente texto é parte de A implantação da Mitsubishi em Catalão: estratégias políticas e territoriais da indústria automobilística nos anos 90, dissertação de mestrado defendida no Instituto de Estudos Sócio-Ambientais, em 2002.

** Professor assistente do Depto. de Geografia do Campus da UFG em Catalão-GO. E-mail: ronaldogeo@hotmail.com 
produtiva.

Compreender a guerra fiscal feita pelos Estados e usada sabiamente pelas corporações automotivas é de suma importância para a Geografia. O conhecimento do uso corporativo do território permite analisar a descentralização industrial e intervir nos impactos socioambientais nas regiões, bem como rever a cobrança e a distribuição de impostos e receitas. Por fim, uma compreensão de todos esses fatores e de suas interações pode auxiliar na elaboração de políticas públicas orientadas para o desenvolvimento. Esses temas devem estar no cerne da Geografia Econômica contemporânea. A análise empreendida neste estudo busca também compreender as razões que levaram a Mitsubishi Motors Company do Brasil ( MMC) a escolher a cidade de Catalão para sediar sua fábrica e assim se tornar a primeira montadora de veículos automotores em escala industrial do Estado de Goiás e da Região Centro-Oeste.

A indústria automobilística brasileira ficou estagnada nos anos 80 , após a euforia de seu desenvolvimento ao longo das duas décadas anteriores. O fechamento do mercado para a importação nos anos 80 , tendo em vista o desenvolvimento autônomo da indústria nacional, criou uma situação especial no país. As indústrias automobilísticas, em particular as quatro gigantes - as americanas General Motors e Ford, a alemã Volkswagen e a italiana Fiat -, dominavam o setor e estavam protegidas pela reserva de mercado, que, assim, afastou a concorrência. Com isso, elas praticavam preços abusivos, oligopolizavam o mercado e não investiam em tecnologia. Com a abertura do mercado pelo governo Collor em 1991, o setor sofreu profundas mudanças.

Além da reabertura do mercado para a importação de carros, outras montadoras foram estimuladas a instalar novas fábricas no Brasil. Com o Plano Real e a queda da inflação em 1994, dezenas de projetos industriais no setor automotivo foram negociadas para breve implantação no país. O Brasil se apresentou, em termos estratégicos, como o país com o maior mercado potencial do mundo nos anos 90. Arbix (1999, p. 55) apresenta as razões desse surto, quando afirma:

Desde 1994 o Brasil se tornou um dos mais importantes alvos dos investimentos 
diretos estrangeiros em todo o mundo. A relativa estabilização da economia brasileira, somada à abertura de setores econômicos essenciais, e a consolidação do Mercosul estão na raiz do crescimento dos investimentos diretos externos (IDE) no Brasil, que teve na indústria automobilística um de seus principais receptores.

A elaboração do regime automotivo foi o primeiro esboço de uma política industrial do governo federal nos anos 90. Não apenas o primeiro, mas também o setor em que o governo Fernando Henrique mais ousou. A adesão ao regime automotivo brasileiro, a partir de 1996, de acordo com Arbix (2000), contou com 16 montadoras, 150 empresas de autopeças e 29 firmas de outros setores produtivos. O Ministério do Desenvolvimento, Indústria e Comércio (MDIC) declarou em 2001 que, entre dezembro de 1995 e setembro de 1998, haviam sido efetivados 10,6 bilhões de dólares no setor, com uma projeção para 14 bilhões até o final de 1999 (Brasil. MDIC, 2001). Os Estados Unidos e o Japão (Pinto, 1999) entraram na Organização Mundial do Comércio (OMC) contra o regime automotivo brasileiro, em função da ousadia em concessões fiscais. ${ }^{1}$ Os números divulgados sobre os investimentos na indústria automobilística são discrepantes e dependerão de quem, acima de tudo, os estiver anunciando. De fato, a dança dos números altera de acordo com o anúncio, se feito em dólares ou em reais, pois varia ao sabor da flutuação da taxa de câmbio.

O capital estrangeiro do setor automobilístico buscou o Brasil nos anos 90, não apenas para investir em novas fábricas e produtos, mas também para comprar as empresas nacionais de autopeças que não conseguiam resistir à reestruturação do setor. Bedê (1997, p. 385) questiona a política industrial do governo federal relativa às montadoras; para ele, as autopeças é que deveriam receber incentivos especiais:

Observe-se, no entanto, que por ser mais intensiva em mão-de-obra é justamente a

1 O Brasil recorreu e venceu. O móvel da ação foi a guerra por indústrias, pois elas significam empregos para a população e impostos para os governos. A indústria automobilística chegou a responder por $11 \%$ do PIB do Brasil. Por exemplo, a Mitsubishi em Catalão gera 600 empregos diretos e muitos outros indiretos. 
indústria de autopeças que apresenta o maior potencial de expansão do emprego. Além disso, frente ao setor montador, o segmento de autopeças apresenta um maior número de imperfeições de mercado. [...] Portanto, se existe um segmento da cadeia produtiva de autoveículos que deveria ser selecionado, o melhor candidato seria o segmento fornecedor de autopeças. (Bedê, 1997, p. 385)

Quase todas as grandes empresas nacionais do setor de autopeças foram absorvidas por empresas estrangeiras. A Tabela 1 ilustra a mudança da propriedade do capital no setor de peças:

\begin{tabular}{ccc}
$\begin{array}{c}\text { Fabela } \\
\text { Ano }\end{array}$ & $\begin{array}{c}\text { Propriectate to eapital no setor de } \\
\text { Nacional }\end{array}$ & Estrangeiro \\
1994 & 52,0 & 48,0 \\
1997 & 40,8 & 59,2 \\
1998 & 38,9 & 61,1 \\
\hline
\end{tabular}

Fonte: Arbix (2000, p. 251)

Nos anos 90, o toyotismo começou a ser adotado na reestruturação da indústria automobilística brasileira, provocando alterações significativas no setor. Esse paradigma organizacional, juntamente com as novas tecnologias aplicadas à produção, levou a uma grande dispensa de força de trabalho, mergulhando a região do $\mathrm{ABC}$ paulista em uma crise sem precedentes. Essa estagnação na área do coração do fordismo brasileiro se tornaria ainda mais dramática na segunda metade dos anos 90, com os investimentos das novas plantas industriais fora de São Paulo. Não apenas as novas montadoras procuraram novas áreas, como também as antigas transferiram seus projetos de ampliação e novos investimentos para fora do ABC. Esse arranjo espacial da indústria automotiva vem produzindo uma nova territorialização, com variadas repercussões nas regiões onde as montadoras se instalam.

Embora o interesse deste trabalho pela acumulação flexível priorize as novas possibilidades locacionais dela resultantes, é importante considerar o 
peso desse novo modelo de acumulação na crise ou no desenvolvimento das regiões. Em 1998, a Associação Nacional dos Fabricantes de Veículos Automotores (Anfavea) calculava que o número de trabalhadores no setor automotivo era de 83 mil pessoas, ${ }^{2}$ e o peso dessas indústrias no total do Produto Interno Bruto (PIB) nacional era de 10,7\%. Um outro dado do gigantismo do empreendimento automobilístico brasileiro era o fato de que, a partir do ano de 2000, o país passaria a contar com 20 marcas de autoveículos sendo produzidas no país. Para se ter uma idéia, os Estados Unidos tinham, em 2001, catorze marcas em seu território. É pelo gigantismo das montadoras e pelo seu significado em empregos - diretos e indiretos - e impostos que a disputa para sediar uma delas torna-se uma competição em escala mundial entre cidades, regiões e países. Maximiano (1997, p.130) destaca o significado das indústrias automobilísticas para o Brasil:

Foram responsáveis pela urbanização do País, pela transformação de grandes contingentes de trabalhadores rurais em trabalhadores urbanos politizados, pela introdução de novos hábitos de consumo, pelo desenvolvimento do sindicalismo e das comissões de fábrica, pelo crescimento e distribuição da riqueza nacional. Fizeram do ABC, até então apenas o "o caminho para o mar", um pólo de modernização industrial e tecnológica, de agitação trabalhista e de formação de lideranças, um centro de influência na vida nacional. Não faltava razão a Drucker quando, nos anos 40, chamou a indústria automobilística de "a indústria das indústrias".

Em 1980, saíram das linhas de montagens no Brasil 1.163 mil veículos. Esse montante colocou o país entre os dez principais construtores mundiais. Dez anos antes haviam sido apenas 416 mil unidades. Com a estagnação tecnológica, a inflação alta e o monopólio de quatro indústrias, foram vendidos 750 mil automóveis no ano de 1989. Nos anos 90, a produção ultrapassou a marca de 1 milhão de automóveis. A logística das multinacionais compreendeu

2 Esse número corresponde a empregos diretos. É difícil calcular o impacto no que tange a empregos indiretos. A rede de empresas, pessoas e serviços envolvidos na montagem de um automóvel entranha-se pelo tecido social adentro, com vastas repercussões econômico-espaciais; daí a justeza da alcunha de "civilização do automóvel", que expressa mais do que a simples presença dos carros nas ruas. 
bem as vantagens em produzir os seus carros no Brasil. Assim como a China, o Brasil tem no ramo de automóveis um dos mercados com um dos maiores potenciais de crescimento no mundo. Esse potencial é visto como maior que o da Europa, Estados Unidos e Japão. A relação de carros por habitantes nesses países já é muito grande, ao passo que, no Brasil, ainda há condições para um crescimento vertiginoso.

Tabela 2 - Habitantes por veículos

\begin{tabular}{cc}
\hline Países & Habitantes/ veículos \\
\hline Brasil & $11,2 / 1$ \\
Argentina & $5,2 / 1$ \\
Japão/ França & $2 / 1$ \\
Alemanha & $1,9 / 1$ \\
Itália & $1,8 / 1$ \\
\hline Estados Unidos & $1,3 / 1$ \\
\hline
\end{tabular}

O Brasil é visto pelas montadoras como um dos maiores mercados "emergentes" do mundo. A estabilização macroeconômica advinda com o Plano Real, com o Mercosul e com a abertura econômica criou, segundo Arbix (1999), as condições que as multinacionais do setor consideravam propícias para fazer do Brasil o país que recebeu ao longo dos anos 90 a maior quantidade de investimentos externos diretos (IEDs) do setor em todo o mundo.

É importante salientar ainda que o preço da força de trabalho no Brasil tornou o país muito atraente para as montadoras. O trabalhador da região do $\mathrm{ABC}$ já oferecia uma força de trabalho com remuneração até quatro vezes mais baixa que a de trabalhadores europeus-ocidentais, estadunidenses e canadenses. A diferença salarial entre a força de trabalho desses países e 
a dos brasileiros aumenta mais ainda se considerar que as empresas, ao saírem do $\mathrm{ABC}$, conseguem força de trabalho por menos da metade do preço do entorno da grande São Paulo. De acordo com Botelho (2000, p. 85), a renda mensal de um metalúrgico do $\mathrm{ABC}$ paulista é de 1.500 reais; em Betim (MG), 800 reais; e em Resende (RJ) é de 400 reais. Em Catalão (GO), os cobiçados empregos da Mitsubishi rendem também ao operário da linha de montagem cerca de 400 reais por mês. Percebe-se claramente que os salários mais baixos, cuja conseqüência é o aumento da taxa de maisvalia, juntamente com os incentivos fiscais, é um dos principais motores da desconcentração industrial.

A pujança desse setor industrial se assenta em grande parte no Decreto-Lei $\mathrm{n}^{\mathrm{o}} 1.761$, de 27 de dezembro, e na Medida Provisória $\mathrm{n}^{\circ} 1.024$, de 28 de dezembro de 1995, do governo federal, que criam uma série de incentivos para as montadoras e autopeças que investirem no país. O regime automotivo foi mais tarde acrescido pela Lei $\mathrm{n}^{\circ} 9.449$, de 14 de março de $1997 .^{3}$

Com a Lei $n^{\circ} 9.449$, o governo federal criou condições ainda mais especiais para as montadoras e autopeças que se instalassem nas regiões Norte, Nordeste e Centro-Oeste. As montadoras que haviam aderido a novas condições, entre 1995 e 1997, tinham endereçado seus investimentos exclusivamente para as regiões Sul e Sudeste. A intenção do governo era uma melhor distribuição desses grandes investimentos com forte impacto no desenvolvimento das regiões. De acordo com Arbix (2000, p. 248), os principais objetivos do Novo Regime Automotivo eram: a) atrair novas companhias, novas plantas e novas marcas; b) manter as grandes montadoras e autopeças instaladas no país; c) reestruturar as empresas brasileiras no setor através de fusão, associação e aquisição; d) consolidar o Mercosul, e nele a posição do Brasil.

$\mathrm{O}$ governo federal concedeu às montadoras e autopeças, em seus

3 Há vários instrumentos legais instituindo o regime automotivo brasileiro, entre os quais as várias medidas provisórias e o projeto de lei acima, que regulamentam o novo e polêmico regime automotivo brasileiro dos anos 90 . A apresentação da Lei 9.449, de março de 1997, e os atos que regulamentam esse regime foram obtidos no site do MDIC (www.mdic.gov.br), aos 14 de setembro de 2001. 
novos investimentos, 2 bilhões de dólares em isenção fiscal, entre 1996 e 1997, através do Regime Automotivo. No mesmo período, de acordo com Botelho (2000), houve uma redução no número de empregos de $21,86 \%$ no setor automotivo. O Tribunal de Contas da União (TCU) fez uma apreciação desfavorável ao montante da renúncia fiscal. Embora não se saiba quais critérios foram utilizados para definir o ranking, o TCU concluiu que, no quesito "geração de empregos", as montadoras ficavam no $38 .^{\circ}$ lugar entre os setores produtivos. Assim, recomendava-se isenção para empresas que gerassem mais empregos com o seguinte parecer:

Sendo um país com farta oferta de mão-de-obra e pouca disponibilidade de capitais, [o Brasil] deveria optar pela aplicação das renúncias de receitas em segmentos econômicos em que houvesse a prevalência do fator trabalho, em vez de propiciar a acumulação de capital nas mãos de poucas empresas, em grande parte controladas pelo capital estrangeiro. (Botelho, 2000, p. 93)

No período do keynesianismo-fordismo, os governos nacionais também forneciam dinheiro público em empréstimos e isenções fiscais à iniciativa privada para projetos industriais. Durante esse período, concomitante ao apoio dado ao capital produtivo, havia um investimento público em saúde, educação, habitação e previdência. Hoje, no neoliberalismo, os gastos sociais são retirados e/ou diminuídos, ao passo que as concessões ao capital se ampliam, inclusive em benefício maior do capital especulativo que do produtivo. O fato é que, atualmente, o capital avança sobre o fundo público com mais ímpeto, sobrando cada vez menos recursos para políticas sociais.

A repercussão espacial dessa lógica se manifesta no seguinte princípio: a cidade, região ou país que abrir mais o fundo público, em benefício do capital, receberá tal ou qual nova fábrica. A isso se acrescenta a dotação do território, que põe umas e outras áreas mais competitivas que as outras. Tal é o caso da posição geográfica de Catalão ao ser escolhida pela Mitsubishi. Uma das teses defendidas neste trabalho é a da posição geográfica como um fator ainda importante na decisão locacional das empresas para a implantação de suas indústrias.

O êxodo da indústria automobilística de São Paulo: guerra dos lugares 


\section{e desconcentração industrial}

Como desenvolver as várias partes do país de forma mais equânime, distribuindo com justiça os resultados da riqueza nacional entre as regiões geográficas que estruturam o corpo da pátria? Grande parte da resposta a essa questão depende do encaminhamento dado ao processo da desconcentração industrial. As razões históricas que determinaram a concentração industrial na região Sudeste, em especial em São Paulo, remontam ao último quartel do século XIX, quando o café emergiu como o ouro negro do Brasil. A acumulação de capitais gerados pela riqueza do café levou o Estado de São Paulo a deslocar o Rio de Janeiro da posição de maior produtor industrial do país, já nas primeiras décadas do século XX. Desde então, a desigual concentração de poder econômico e político em favor de São Paulo e da região Sudeste aumentou exponencialmente durante o século XX e, com ela, as desigualdades entre as regiões brasileiras. Com os estadistas Getúlio Vargas e Juscelino Kubitschek, a sorte das demais regiões começou a mudar. O Brasil passou a olhar e a caminhar para dentro de si. Sertão e litoral se encontrariam mais e mais.

Por que o êxodo das indústrias automobilísticas do Estado de São Paulo causou tanto debate e embate entre governadores, sindicalistas, empresários e estudiosos? As regiões e os Estados não-industrializados e/ou com pouca presença de indústrias reclamam que precisam mudar o seu perfil econômico, e que historicamente São Paulo foi mais beneficiado. Por sua vez, São Paulo reclama da concorrência desleal e ilegal das demais unidades da federação, referente aos incentivos para atração de indústrias, além de se queixar da perda de empregos. De 1995 em diante, quando as montadoras começaram a anunciar investimentos fora de São Paulo, a imprensa noticiou muitas "farpas" entre os governadores dos Estados envolvidos e também de outros que estavam fora da disputa. A revista Época, de 19 de julho de 1999, informava: "Mário Covas acha que é um erro permitir a ida da Ford para a Bahia a bordo de um caminhão de incentivos fiscais e empréstimos públicos". Já a Folha de S. Paulo, de 29 de julho de 1999, anunciava:

O governador gaúcho, Olívio Dutra (PT), enviou ontem carta ao presidente Fernando Henrique Cardoso com queixas sobre o comportamento da União em relação ao Rio Grande do Sul, especialmente quanto à ida da Ford para 
a Bahia, e anunciou que entrará com uma medida judicial contra o governo federal.

A guerra dos lugares pela instalação das empresas não ocorre apenas entre cidades e regiões de um mesmo país, como acontece no Brasil. Ela é uma disputa dramática de cada cidade ou região contra todas as outras - essa é uma marca da globalização. A produção de conhecimento, conforme nos lembra Chesnais (1996), está concentrada nos países da tríade Estados Unidos, Comunidade Européia e Japão. Com essa divisão, resta aos demais países disputar ao menos as localizações industriais. A produção de tecnologia, conhecimento e informação, tal como ocorre hoje, deixa os países pobres bem distantes de seu acesso, ou seja, mais pobres ainda.

No Brasil, a disputa pelos investimentos industriais foi mais polêmica entre as montadoras de automóveis, em função dos elevados volumes de capitais investidos em empreendimentos desse porte, dos impostos gerados e dos empregos indiretos decorrentes. O principal instrumento de luta entre os Estados é baseado na renúncia fiscal ao imposto sobre a circulação de mercadorias e serviços (ICMS). Esse imposto ${ }^{4}$ é a mais importante fonte de arrecadação para a maioria dos Estados e municípios. Para Catalão, o ICMS representava em 2002 cerca de $55 \%$ da arrecadação total do município. A Reforma Tributária do Governo Federal (2003) do presidente Lula visa diminuir a renúncia fiscal (fruto da guerra interestadual) e evitar mais perda de arrecadação aos cofres públicos, entre outros objetivos. Mas as forças políticas e os interesses econômicos em jogo não permitem prever o resultado final dessa reforma.

O Estado de Goiás, através do seu programa de industrialização, o Produzir - cujo nome antes de 1998 era Fomentar, e que após essa data sofreu poucas alterações -, financia para as indústrias que se instalarem em Goiás até $73 \%$ do imposto devido, sendo que a empresa recolhe apenas $23 \%$ do total. Esse, entre outros recursos, foi utilizado para a atração da Mitsubishi para o Estado de Goiás.

O Supremo Tribunal Federal manifestou-se, recentemente, contra os Estados do Paraná e Mato Grosso do Sul pela desvinculação abusiva de receitas em favor de empresas privadas. Essa prática tem sido considerada lesiva ao erário público e muito benéfica às empresas particulares. As montadoras, 
além das vantagens do regime automotivo do governo federal que isentam ou diminuem o imposto incidente sobre peças e maquinarias importadas, contam com a isenção do ICMS dos governos estaduais e a do imposto predial territorial urbano (IPTU) nos municípios onde se instalam. A Tabela 3 mostra a arrecadação de ICMS em algumas unidades da federação, dentre elas Goiás, e o seu peso relativo em relação ao total do Brasil.

Tabela 3 - Arrecadação de ICMS em 1999

\begin{tabular}{lrc}
\hline $\begin{array}{c}\text { Fonte: COTEPE/CONFAZ } \\
\text { EsTADo }\end{array}$ & $\begin{array}{c}\text { apud Goiás (2001) } \\
\text { (RS) }\end{array}$ & $\begin{array}{c}\text { \% EM RELAÇÃo } \\
\text { AO BRASIL }\end{array}$ \\
\hline São Paulo & $26.292 .499 .000,00$ & 39,48 \\
\hline Minas Gerais & $6.306 .922 .000,00$ & 9,47 \\
\hline Goiás & $1.774 .831 .000,00$ & 2,66 \\
\hline Piauí & $341.556 .000,00$ & 0,51 \\
\hline Amapá & $61.337 .000,00$ & 0,09 \\
\hline Acre & $57.375 .000,00$ & 0,08 \\
\hline Total Brasil & $66.587 .893 .000,00$ & 100,00 \\
\hline
\end{tabular}

A Tabela 3 mostra, com clareza, através dos dados sobre a arrecadação do ICMS, como esse imposto é concentrado em São Paulo. Esse Estado sozinho comparece com 39,48\% da arrecadação desse importante imposto, ou seja, a riqueza do país se concentra de forma nociva para quem defende uma distribuição mais bem repartida do fundo público pelo território nacional. Dados como esse animam o bate-boca entre os governos estaduais em torno da guerra fiscal. Mário Covas, o governador de São Paulo pelo Partido da Social Democracia do Brasil (PSDB), no período de 1999 a 2000, estranhamente expressou a sua solidariedade ao Rio Grande do Sul - Estado governado pelo 
Partido dos Trabalhadores (PT), partido de oposição -, conforme mostrou a revista Época (19/07/99), por ter perdido a Ford para a Bahia. Em verdade, é uma defesa velada de São Paulo, que tem perdido montadoras de automóveis, inclusive para o Rio Grande do Sul.

A pressão de imigrantes de outras regiões sobre os recursos industriais concentrados nas metrópoles do Sudeste levou a região mais rica do país, especialmente São Paulo, a diminuir drasticamente as possibilidades de geração de emprego, o que gerou a queda da qualidade de vida da maioria (desempregados e empregados). É claro que, além da explosão populacional dessa metrópole, deve ser considerado o baixo crescimento econômico do país em função de macropolíticas econômicas desajustadas e do pesado endividamento interno e externo. Há que se considerar ainda a reestruturação da cidade em virtude de sua inserção na globalização, das novas tecnologias e das políticas neoliberais para o mundo do trabalho. Devem ser acrescidas também a esse quadro a infra-estrutura urbana deteriorada, a poluição e a violência, entre outros inúmeros problemas. Essa situação deveria levar os governantes de São Paulo a desejarem uma política federal de descentralização industrial. Uma iniciativa federal acordada com os governos estaduais, com o uso do fundo público, poderia ter, quem sabe, bons resultados sociais, com uma melhor distribuição da infra-estrutura urbana, territorial e industrial para as demais regiões. Uma ação como essa não resolveria os problemas das metrópoles do Sudeste, mas aliviaria, certamente, as enormes demandas sociais existentes.

Outros fatores também refletem na retirada da indústria automotiva desse Estado. As empresas, por iniciativa própria, vêm deixando a zona do $\mathrm{ABC}$, não apenas pelos incentivos fiscais, mas também pela queda de produtividade que essa área começa a apresentar em função da excessiva aglomeração industrial. $\mathrm{O}$ encarecimento do terreno urbano e dos arredores cria uma dificuldade crescente para atividades produtivas que requerem vastas áreas. $\mathrm{O}$ congestionamento de trânsito e o saturamento das vias tornam mais lentas a chegada de matériasprimas e a saída de produtos industrializados. A poluição do solo e do ar torna algumas atividades impraticáveis, e a poluição da água potável dificulta a fabricação de remédios e produtos alimentícios, entre outros.

Os problemas arrolados provocam o aumento dos gastos estatais com saúde pública. Para fugir dessa situação, empresas, executivos e altos funcio- 
nários têm procurado cidades médias no interior. São cidades que dispõem de universidades, áreas de lazer, áreas verdes e vários outros itens capazes de garantir uma qualidade de vida melhor aos trabalhadores de média e alta qualificação, que têm assim a opção de se deslocar dos grandes centros.

A região Centro-Oeste foi, nos anos 80, uma avançada fronteira agrícola. Nos anos 90, ela não apenas ampliou a produção agrícola como também se transformou em fronteira agroindustrial. As empresas de produtos alimentares têm investido nessa vocação decorrente da atividade agrícola que está na base da cadeia produtiva da região Centro-Oeste. Santos \& Silveira (2001, p. 107) apontam essa tendência quando salientam que a região Centro-Oeste começa a ter um papel no quadro industrial, abrigando várias etapas da cadeia produtiva das mais poderosas agroindústrias sulistas e evidenciando também a alta concentração de capitais e a automação dos processos produtivos". Segundo os autores, "por outra parte, as fronteiras agropecuárias modernas do Centro-Oeste tornam-se agora novas fronteiras industriais, 'externas' à Região Concentrada, e abrigam um número pequeno de poderosas industriais” (p. 109).

Catalão, situada na microrregião do sudeste goiano, a 270 km de Goiânia, é um exemplo das novas fronteiras industriais externas à região concentrada. Esse município é um destacado produtor de soja, milho, mandioca, alho e produtos minerais, como fosfato e nióbio. Hoje sua produção passa por uma diversificação com a chegada das montadoras Mitsubishi (comerciais leves) e Cameco (máquinas colheitadeiras de cana-de-açúcar e algodão). A empresa Copebras - prudutora de fosfato -, instalada desde os anos 70 na cidade, investiu nos últimos três anos 148 milhões de dólares na verticalização dos produtos do fosfato. Esses novos empreendimentos influenciam também o setor terciário ao injetarem mais dinheiro na cidade através de seus funcionários e, principalmente, de seus executivos, engenheiros e gerentes, que demandam produtos e serviços mais sofisticados, até então inexistentes.

$\mathrm{O}$ aumento da arrecadação municipal tem ampliado consideravelmente a capacidade da prefeitura de intervir na infra-estrutura urbana e aumentar a prestação de serviços à população. Tanto o Estado como a cidade já vislumbram uma fase de desenvolvimento em que outras indústrias, além das extrativas e de transformação de produtos alimentares, buscarão se implantar em seu território. Juntamente com os investimentos, novos serviços virão, inclusive, na 
produção da informação e do conhecimento, notadamente com a expansão da Universidade Estadual de Goiás (UEG) e dos campi da Universidade Federal de Goiás (UFG) em Catalão (sudeste) e Jataí (sudoeste).

Contudo, os dados econômicos (Revista de Economia e Desenvolvimento, 2001) ainda mostram a prevalência das atividades oriundas das raízes agrárias de Goiás. Os produtos alimentares respondem por $29,95 \%$ de nossa produção industrial. $\mathrm{O}$ vestuário, os calçados e artefatos de tecido respondem por 27,18\%; os minerais não-metálicos representam 7,87\%; e a metalurgia responde por 6,24 .

Retornando à concentração industrial em São Paulo, vale dizer que, na disputa interestadual pelas plantas automobilísticas, o Estado tem nessa força, contraditoriamente, a sua fraqueza. Esse Estado, o Leviatã industrial da formação socioterritorial brasileira moderna, não pode oferecer às montadoras os benefícios fiscais que os outros Estados lhes oferecem. Se isenções ousadas forem dadas a uma montadora mais recente, aquelas pioneiras, que se instalaram na região do $\mathrm{ABC}$ desde os anos 60, vão reclamar as mesmas condições. A generalização de um benefício como esse para os newcomers ${ }^{5}$ e para antigos fabricantes poderia gerar um rombo enorme no fisco estadual, fazendo da permanência delas, em São Paulo, uma vitória muito cara.

Não se deve esquecer, além das deseconomias geradas pela grande aglomeração industrial, o papel da força de trabalho barata e não sindicalizada ou sem tradição sindicalista aguerrida. No caso da região do $\mathrm{ABC}$, o seu operariado é o mais combativo e organizado do país. Nenhuma outra região do Brasil pode causar ao capital representado pelas montadoras tantas dificuldades, como, por exemplo, greves, mobilizações com variadas estratégias, negociações coletivas, enfim, a mais organizada pressão operária do país. Essas condições e experiências acumuladas de luta resultam nos mais altos salários entre os trabalhadores-operários do país.

Quanto aos IEDs da indústria automotiva, estes querem o máximo

5 Os newcomers são as montadoras ou novos investimentos no setor recém-chegados ao país nos anos 90. Essa é a expressão anglófona usada pelo governo nas medidas provisórias e no projeto de lei que estabelecem o regime automotivo brasileiro. 
de lucro, explorando o máximo de mais-valia, com o mínimo de problemas trabalhistas. Embora o governo federal tenha mudado as leis trabalhistas, e os operários se sintam ameaçados de perder o emprego, as empresas também tomam as suas iniciativas. Uma delas - decisiva logo no ponto de partida - diz respeito à escolha da localização geográfica da indústria.

Várias montadoras têm permanecido no Sudeste e mesmo no interior paulista, mas a fuga da região do $\mathrm{ABC}$ é fato considerável. Entretanto, mesmo deixando São Paulo, essas montadoras continuam nas regiões concentradas, ou seja, Sudeste e Sul. Nessas regiões estão a melhor infra-estrutura territorial produtiva, os melhores serviços públicos e o maior mercado consumidor do país. Os maiores beneficiários da desconcentração da indústria automobilística de São Paulo têm sido os Estados do Paraná, Minas Gerais, Rio Grande do Sul, Bahia e Rio de Janeiro. Mesmo assim, São Paulo também recebeu nos anos 90 os investimentos da VW em São Carlos, da GM em Moji das Cruzes, da Toyota em Indaiatuba, da Honda em Sumaré e da Kia em Itu - o que mostra que o interior paulista também recebe investimentos que outrora se dirigiam para a região metropolitana. De acordo com Santos \& Silveira (2001, p.121), "a política territorial das corporações automobilísticas, que até recentemente buscava as benesses das localizações metropolitanas, a estas acrescenta hoje ações de descentralização industrial e coloniza novas porções do território".

O Estado de São Paulo ainda recebeu vários IEDs das montadoras nos anos 90, um total de aproximadamente oitocentos milhões de dólares, de acordo com dados da Associação Nacional de Fabricantes de Veículos Automotores (ANFAVEA). No entanto, há um forte movimento das montadoras no sentido de deixar a região do $\mathrm{ABC}$.

Para Arbix (2000), há várias razões que orientam a desconcentração industrial das montadoras. Primeiro vêm os custos trabalhistas - o custo da hora trabalhada no ABC é praticamente o dobro do das outras regiões. E com relação a esse fator podem-se acrescentar os mercados em expansão e a redução do gap educacional - educação de qualidade é uma realidade em muitas cidades do interior de outros Estados fora de São Paulo. Depois vem a decisão de afastarse de áreas com forte organização sindical. E finalmente, a expansão/criação da infra-estrutura territorial rodoferroviária nas outras regiões do país, além da expansão do trabalho qualificado e da degradação da infra-estrutura no ABC. 
Segundo o autor, essas causas ainda são insuficientes para explicar o êxodo das montadoras de São Paulo. O fator mais preponderante para ele é a guerra fiscal entre Estados e municípios. A Tabela 4, de acordo com a pesquisa feita pela Confederação Nacional da Indústria, mostra um ranking das causas.

Tabela 4 - Razões da instalação de novas plantas (\%)

Fonte: CNI/CEPAL, apud Arbix (2000, p. 256)

Todos esses fatores são importantes no entendimento das razões da escolha de Catalão pela MMC. Os benefícios fiscais e as vantagens específicas da localidade, como, por exemplo, a posição geográfica do município, são especialmente considerados nas reflexões deste estudo.

A Tabela 5 demonstra as novas mareas automobilístieas, o volume dos

RAZÕES

$\%$

\begin{tabular}{lc}
\hline Proximidade do mercado & 57,3 \\
\hline Beneficios fiscais & 57,3 \\
\hline Custo da mão-de-obra & 41,5 \\
\hline Vantagens específicas das localidades & 39,0 \\
\hline Sindicalismo atuante & 24,4 \\
\hline Saturação espacial & 14,6 \\
\hline
\end{tabular}

investimentos no setor e a desconcentração industrial de São Paulo.

Tabela 5 - IEDs, novas marcas e novas plantas (1996-2001)*

Fonte: Arbix (2000, p. 250)

*A tabela foi transcrita sem modificações, exceto quanto ao destaque feito para Goiás/Mitsubishi. Cabe esclarecer que a capacidade anunciada é a quantidade de veículos que em tese podem ser produzidos anualmente pela unidade.

** Produção de motores

*** Produção de autopeças 
SILVA, Ronaldo da. Indústria automobilística brasileira nos anos de 1990: uma nova territoria-

Como se pode ver pela Tabela 5, os Estados do Paraná e Minas Gerais têm um destaque maior na atração dos investimentos das montadoras Octararaná

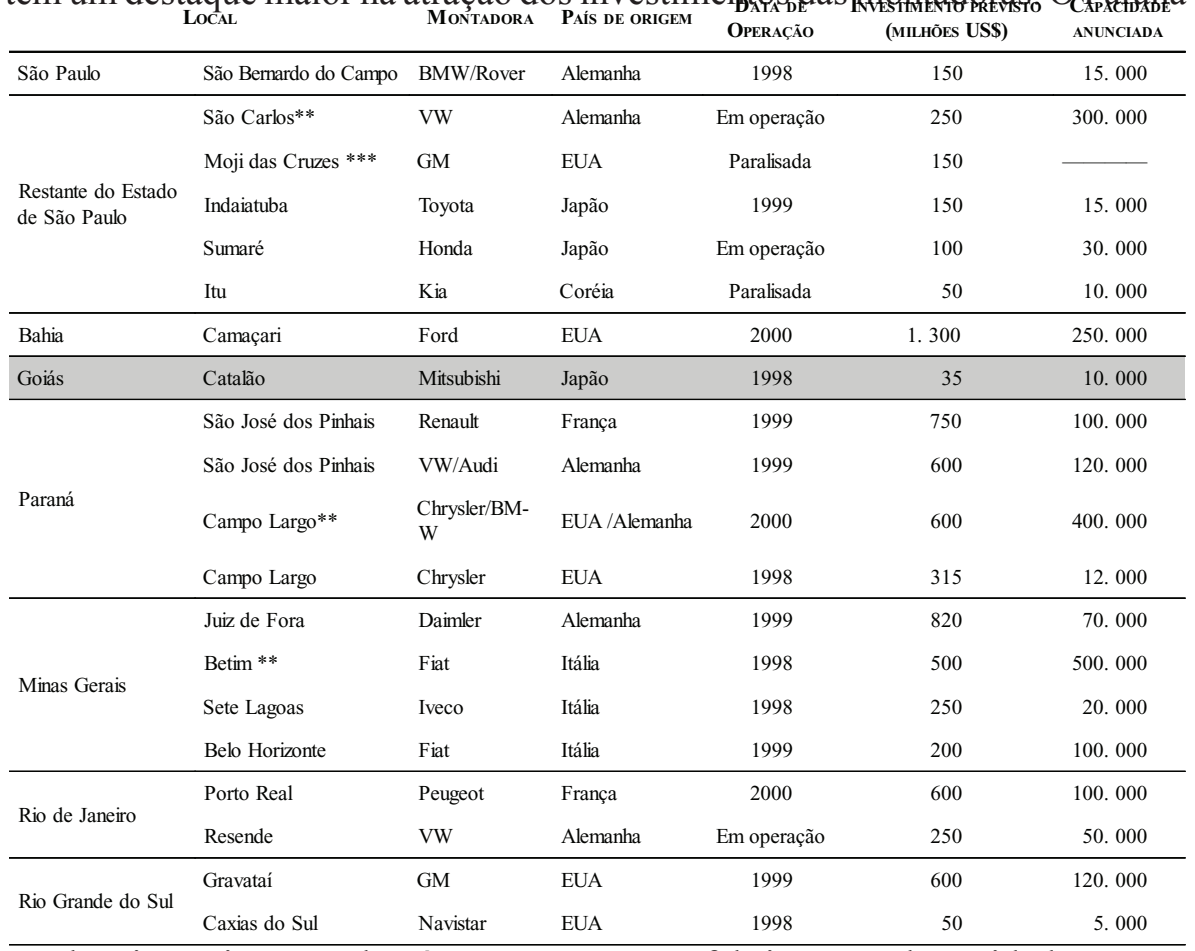

$\overline{\text { recebeu investimentos de três marcas e quatro fábricas, em duas cidades, o que }}$ resultou em um total de 2.265 bilhões. Esse estado ainda é de longe o maior beneficiário dos investimentos das montadoras de automóveis. A revista Isto $E$, de 15 de julho de 1998, p. 99, descreve bem as transformações em curso ao alcunhar a região metropolitana de Curitiba de ABC do Paraná: "O mercado imobiliário anda agitadíssimo. Quase quatro mil imóveis residenciais foram vendidos em junho e muitos donos de chácaras próximas às fábricas colocaram os bens no cadastro das imobiliárias."

No que tange à preferência das montadoras pelo Paraná, a revista Isto É (p. 119) afirma:

Elas foram atraídas para a região por causa da boa qualidade da mão-de-obra local, da eficiente infra-estrutura e da proximidade de mercados potenciais 
- como São Paulo, Rio de Janeiro e Mercosul. Mas acima de tudo morderam a isca da torrente de incentivos federal (regime automotivo), estadual (dilatação dos prazos do ICMS) e municipal (isenção do IPTU).

A Ford deixou o Rio Grande do Sul depois que o governador do Estado, eleito em 1998, procedeu a uma revisão das isenções e de outros compromissos feitos na administração anterior com a empresa. O acordo era lesivo ao Estado, na medida em que 48 milhões de reais já haviam sido gastos pelo Rio Grande do Sul nos preparativos para a instalação da montadora. Além dessa ruptura de benefícios, a Ford deparou-se com o fato de que o Sul não recebia os incentivos fiscais concedidos pela Lei Federal 9.440, que se restringiam às regiões Norte, Nordeste e Centro-Oeste. Com respeito a essa lei, ao expirar o prazo de inscrição para recebimento do benefício, o governo federal prorrogou o tempo através de uma polêmica medida provisória. Com isso, a fábrica foi para a Bahia, conseguindo receber os incentivos federal e estadual. Para tanto, houve muita pressão da bancada baiana no Congresso, liderada, à época, pelo senador Antônio Carlos Magalhães (PFL- BA). Esse ato da administração federal representou a perda da alta quantia de dinheiro público já investida pelo governo do Rio Grande do Sul. Mas, pior que isso, representou um estímulo à guerra fiscal, quando o papel da administração federal seria o de dirimir as querelas em favor do interesse público.

Arbix (1999) critica a ação do governo federal no que tange a sua intervenção na guerra fiscal, argumentando que com ela o poder público se enfraquece, ao passo que aumenta o poder das corporações privadas sobre o fundo público. Os governos, aponta o autor, perdem as prerrogativas de planejadores, e o poder real fica com as empresas. Não há também transparência na prestação de contas para a população, e nem fiscalização adequada. A retórica dos governantes e de seus apoiadores políticos em defesa das isenções restringe-se ao progresso, ao emprego e ao desenvolvimento. Além do que as isenções de ICMS são feitas ao arrepio da lei. Nesse sentido Arbix (1999, p. 65) aponta:

Esse processo, estimulado pelo governo federal com a edição do novo Regime Automotivo, vem cada vez mais possibilitando que políticos regionais distribuam incentivos, subsídios e isenções fiscais como forma de atrair grandes empresas para seus territórios. Perseguindo a imagem de modernizadores e geradores de 
emprego, mergulham em uma disputa sem fim, aumentando indiscriminadamente a transferência de recursos públicos para o setor privado. Essa disputa, conhecida como "guerra fiscal", tornou-se norma na indústria automobilística. As montadoras que planejam construir novas plantas aproveitam-se dessa situação e aproximam-se ao mesmo tempo de vários estados, colocando-os em situação de competição, a fim de alcançar a oferta mais adequada aos seus interesses.

\section{Considerações finais}

Na medida em que as unidades federativas fazem leilões para disputar as montadoras e outras indústrias, oferecendo-lhes os menores impostos, em longo prazo, a arrecadação tende a diminuir drasticamente. Para sanar as finanças, os Estados aumentam ainda mais as taxas a serem pagas pelo consumidor final, ou seja, pela maioria do povo. A manutenção da infra-estrutura territorial, assim como os serviços públicos, pode ficar gravemente comprometida com a queda na arrecadação.

Quanto aos empregos indiretos, estes nem sempre correspondem à expectativa criada pelas montadoras nos Estados e cidades que as acolhem. Para se ter uma idéia, a Toyota, em São Paulo, assim como a Mitsubishi em Goiás, começou sua produção com cerca de $55 \%$ das peças importadas, quando se sabe que $90 \%$ da indústria brasileira de autopeças está localizada em São Paulo. Tal concentração parece causar uma inércia geográfica, favorável a que as montadoras não deixem o maior centro produtor e consumidor, a região centro-sul, onde se situa a melhor malha rodoviária do país. Com isso as promessas de empregos indiretos em outras cidades e Estados podem não se realizar.

No caso da MMC em Catalão, por exemplo, nenhuma produtora de peças veio para a cidade. O número de peças importadas para os carros dos anos 90 minou a euforia em relação à geração de empregos. É válido notar outro aspecto importante: a quantidade de itens de peças de automóveis importados favorecida pelo regime automotivo contribuiu fortemente para a balança comercial negativa no saldo entre exportação e importação por alguns anos. Santos \& Silveira (2001, p. 112) criticam o otimismo desenvolvimentista trazido pelas montadoras: "Nada se fala sobre a robotização do setor, a drenagem dos cofres públicos para o subsídio das atividades, a monofuncionalidade dos portos e de outras infra-estruturas, os royalties e o aumento da dívida externa, a importação 
de peças e de veículos completos."

No que tange à participação na arrecadação, especificamente no Estado de Goiás, este parece ter se beneficiado nos anos 80 e 90 com um ousado índice, em virtude de seu sucesso na competitividade territorial pela atração de indústrias. Hoje é como se o Estado estivesse dando um tiro no próprio pé ao insistir nesse mecanismo. As empresas já instaladas e que contribuem para o fisco reclamam das vantagens dadas às outras recém-chegadas. Estabelece-se um sistema de concorrência desigual entre as empresas subsidiadas e as não subsidiadas.

A nova territorialização se expressa nas diversas opções locacionais tomadas pelas indústrias de automóveis (leves) quando se retiram investimentos do Estado de São Paulo ou se realocam os novos capitais do setor em estados como Goiás, Rio de Janeiro, Minas Gerais, Paraná e Rio Grande do Sul, conforme mostra a Tabela 5. Essas opções locacionais (Tabela 4) visam minar a organização trabalhista mais organizada e sindicalizada do país, a da região do ABC paulista, e ao mesmo tempo tirar vantagens da tecnificação e da informacionalização do território, que só agora reúne as condições sociais e materiais para uma desconcentração industrial mais arrojada nesse setor econômico. $\mathrm{O}$ território, nas novas condições, se mostra não apenas palco da produção, mas também um fator produtivo de acordo com a densidade técnica que ele possui. A diferenciação produtiva dos lugares tem sido mais sabiamente utilizada pelas empresas. Os governos - nacional, estaduais, municipais -, assim como os trabalhadores, têm tido dificuldade em combater ou tirar melhor proveito da leitura geográfica do território feita pelas montadoras. Aliás, na maioria dos casos, como revela a guerra fiscal, os governos têm se comportado como agentes das empresas em detrimento do bem público.

Independentemente das ações fiscais do Estado, há uma concorrência entre os lugares. Essa concorrência, acelerada pela globalização das relações capitalistas, produz uma disputa que ultrapassa as fronteiras nacionais. É preciso, ainda assim, que iniciativas no âmbito federal sejam tomadas como projeto de Brasil no que tange à desconcentração industrial e, por conseguinte, dos recursos. Sendo esse um projeto de coordenação nacional, a visão totalizante do território nacional deve emergir em detrimento da disputa dos governos subnacionais - estados e prefeituras. Essa iniciativa, se tomada, poderá fortalecer o patrimônio público, além de levar à diminuição das desigualdades regionais 
e ao enfraquecimento do apetite privado e seu avanço sobre o fundo público.

\section{ABSTRACT \\ Brazilian automotive industry in the 90's: a new territorialization}

This article aims to understand the new territorial configuration of the automobile industry in Brazil during the 90's. In this period, Brazil was one of the most important countries world wide to receive Direct Foreign Investment. Stable currency, a larger insertion into globalization process and openning market policies created the basis desired by the multinational coorporations in the automobile sector. There has been also a competition among States and Municipal governments (tax war) with ruinous consequences to the public fund, to regional development and for the Brazilian republican system. This article seeks to analyse the new structure of the automobile industry as well as its geographical reorganization that before was concentrated in São Paulo and today spreads (to other regions) through the country.

Key words: Automotive industry/ Tax war/ New territorialization.

\section{REFERÊNCIAS}

ARBIX, Glauco. Política industrial e o lasseiz-faire na guerra fiscal. In: RATTNER, Henrique (Org.). Brasil no limiar do século XX. São Paulo: Edusp, 2000 .

ARBIX, Glauco; POSE-RODRIGUES, André. Estratégias do desperdício: a guerra fiscal e as incertezas do desenvolvimento. Novos Estudos CEBRAP, São Paulo, n. 54, p. 55-71, 1999.

BEDÊ, Marco Aurélio. A política automotiva nos anos 90. In: ARBIX, G.; ZILBOVICIUS, M. De JK a FHC: a reinvenção dos carros. São Paulo: Scritta, 1997. p. 357-387.

BOTELHO, Adriano. Do fordismo à acumulação flexível: a produção do espaço num contexto de mudança das estratégias de acumulação do capital. 2000. 148 f. Dissertação (Mestrado em Geografia) - Faculdade de Filosofia Letras e Ciências Humanas da Universidade de São Paulo. São Paulo, 2000. 
BRASIL. Decreto-Lei n ${ }^{\circ}$ 9.440, de 14 de março de 1997. Estabelece incentivos fiscais para o desenvolvimento regional e da outras providências. Disponível em < http://www.mdic.gov.br>.Acesso em: 03 set. 2001.

BRASIL. Ministério do Desenvolvimento, Indústria e Comércio. Perguntas mais freqüentes sobre o Regime Automotivo. Disponível em: < http://www. mdic.gov.br >. Acesso em: 3 set. 2001.

CATALÃO. Prefeitura Municipal. Procuradoria Jurídica; MMC - AUTOMOTORES DO BRASIL. Protocolo para a implantação de indústria montadora de veículos Mitsubishi. Goiânia, 6 de junho de 1997.

CHESNAIS, François. A mundialização do capital. São Paulo: Xamã, 1996. $335 \mathrm{p}$.

GOIÁS (Estado). Secretaria Executiva do Produzir/Fomentar; Secretaria da Indústria e Comércio; Secretaria da Fazenda. A importância econômica e social da industrialização para Goiás e para o Brasil, Mimeografado.

GOIÁS INDUSTRIAL. De São Paulo para Goiás, a hora e a vez de Catalão. Revista do Sistema Federação das Indústrias do Estado de Goiás (FIEG), Goiânia, n. 175, p. 35-36, jan./fev. 2000.

GONZÁLEZ, Christianne. BNDS dará R\$ 700 milhões à Ford. Folha de $S$. Paulo, São Paulo, 29 jun. 1999. Dinheiro, p. 2-3.

MAXIMIANO, Antônio C. Amaru. Volkswagen do Brasil: a fábrica de caminhões de Resende. São Paulo: ABAMEC-FGV, 1997. Prêmio Mario Henrique Simonsen/Concurso Nacional de "Case Studies". p. 127-134.

PINTO, Costa Luiz. Entre ACM e a OMC. Época, Rio de Janeiro, n. 61, p. 20-22, jul. 1999.

Revista de Economia e Desenvolvimento. Goiânia, ano 2, n. 8, jul./set. 2001. Trimestral.

SANTOS, Milton; SILVEIRA, Maria L. O Brasil: território e sociedade no início do século XX1. Rio de Janeiro: Record, 2001. 471 p.

SILVA, Ronaldo da. A implantação da Mitsubishi em Catalão: estratégias políticas e territoriais da indústria automobilística brasileira nos anos 90.2002. 143 f. Dissertação (Mestrado em Geografia) - Instituto de Estudos Sócio Ambientais da UFG. Goiânia, 2002. 
SILVA, Ronaldo da. Indústria automobilistica brasileira nos anos de 1990: uma nova territoria-

VIEIRA, André. O ABC do Paraná. Isto É, São Paulo, n. 1.502, p. 98-119, 15 jul. 1998.

Recebido em: 15/5/2003 Aprovado em: 10/12/2003 